\title{
Intrapartum fever for primiparous parturients: causing factors and effect on neonate
}

Lindžiütè U. ${ }^{1}$, Saulènas T. ${ }^{1}$, Baliulienè V. ${ }^{2}$, Rimaitis K. ${ }^{2}$, Macas A. ${ }^{2}$

${ }^{1}$ Lithuanian University of Health Sciences, Lithuanian University of Health Sciences, Kaunas, Lithuania,

${ }^{2}$ Lithuanian University of Health Sciences, Dept of Anesthesiology, Kaunas, Lithuania

\section{Background and Goal of Study}

Fever during labour and delivery occurs in $1.6-14.6 \%$ of deliveries. Maternal fever is associated with higher risk of adverse neonatal and maternal outcomes. The controversy exists about the factors that could affect the rise of temperature during labour.

The aim of this study was to determine factors causing intrapartum fever for primiparas and to find out the effect on neonate.

\section{Materials and Methods}

The study was carried out at the Department of Obstetrics of a teaching hospital in 2015. Medical records of 543 women were retrospectively reviewed. Primiparas at gestational age $\geq 37$ weeks, giving vaginal birth with singleton cephalic presentation and normal weight fetus were included. Local Ethics Committee approval was obtained.

Data were analysed with the SPSS 23.0. Spearman Rank

Correlation, Mann-Whitney $U$ test, $X^{2}$ and Logistic Regression were used. $P<0.05$ was considered statistically significant.

\section{Results and Discussion}

Among 543 primiparas average age was $28.38 \pm 5.89$ years, weight gain during pregnancy $15.14 \pm 6.40 \mathrm{~kg}$, $49.72 \%$ gained $<15 \mathrm{~kg}, 50.28 \% \geq 15 \mathrm{~kg}$, BMI $22.71 \pm 5.02$, labour period $647 \pm 201 \mathrm{~min}$, anhydrous period $465 \pm 329$ min. Epidural analgesia was selected in $32.78 \%$ cases. Intermittent epidural bolus were used in $7.93 \%$, bolus and continuous epidural infusion $82.38 \%$, patient controlled analgesia $9.69 \%$ cases. Average duration of epidural was $413 \pm 220 \mathrm{~min}$. The rate of intrapartum fever $\left(\geq 37^{\circ} \mathrm{C}\right)$ $32.6 \%$, hyperthermia $\left(\geq 38^{\circ} \mathrm{C}\right)-3.3 \%$.
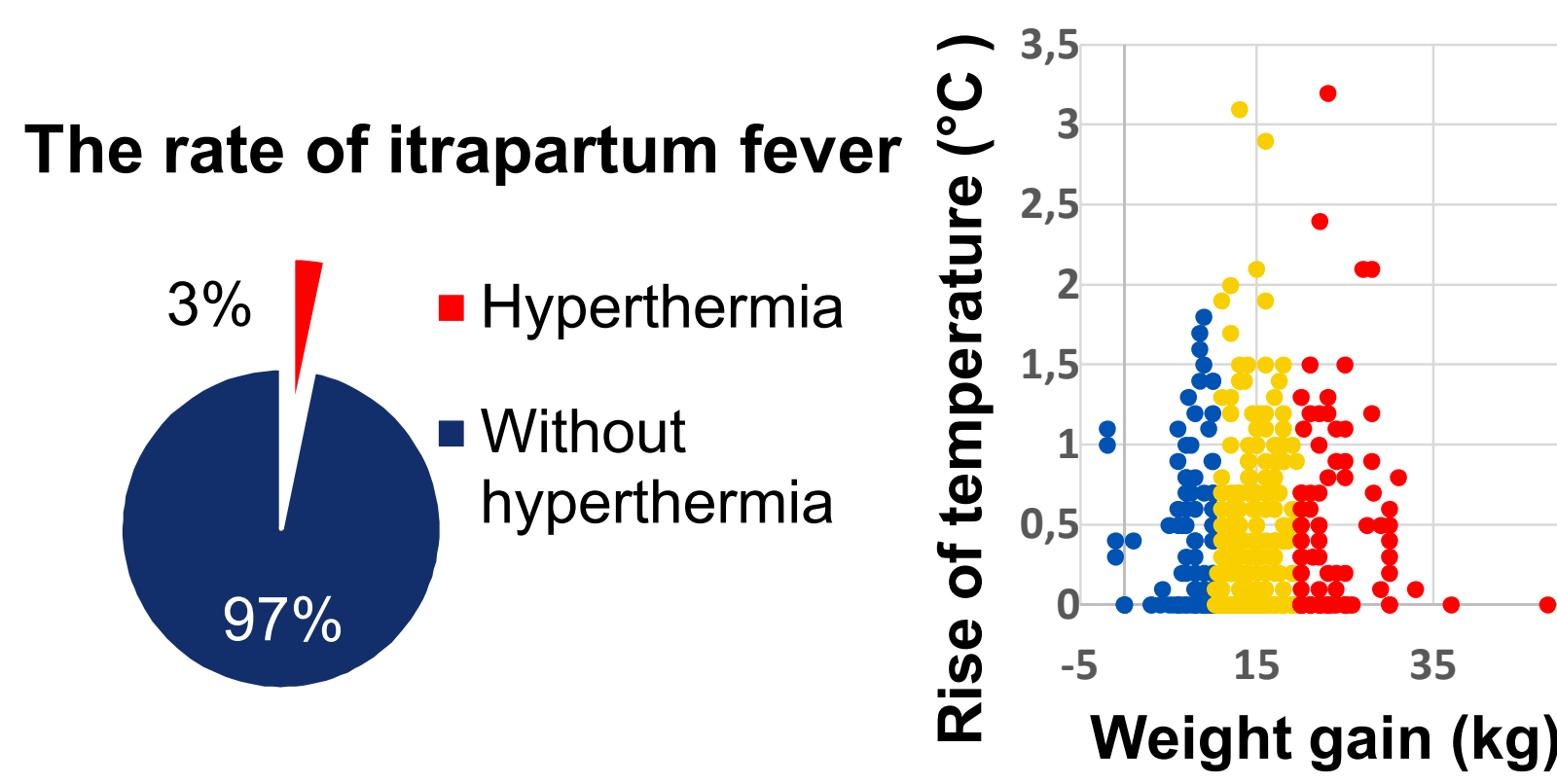

Elevation of body temperature was not significantly associated with weight gain $\geq 15 \mathrm{~kg}$ during pregnancy (OR $0.980(95 \% \mathrm{Cl} 0.722-1.330), p=0.896)$, but the occurance of fever was associated with obesity (KMI $\geq 30$ ) $(p<0,001)$.

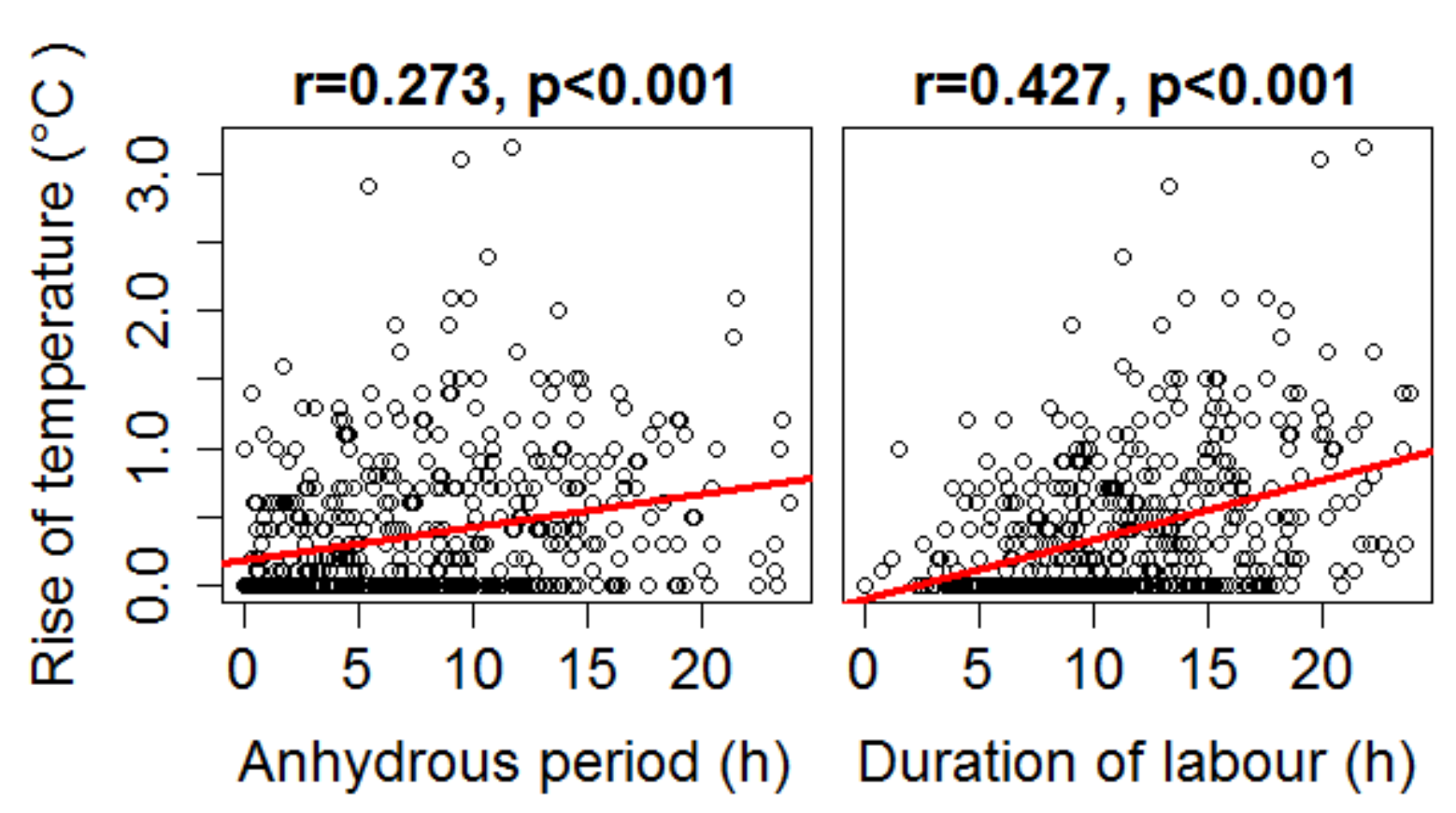

Elevation of body temperature was not significantly associated with the choice of epidural analgesia during labour $(x 2=0.001, p=0.980)$, the duration of epidural $(r=0.1, p=0.182)$, the mode of prescription of epidural $(p=0.417)$.

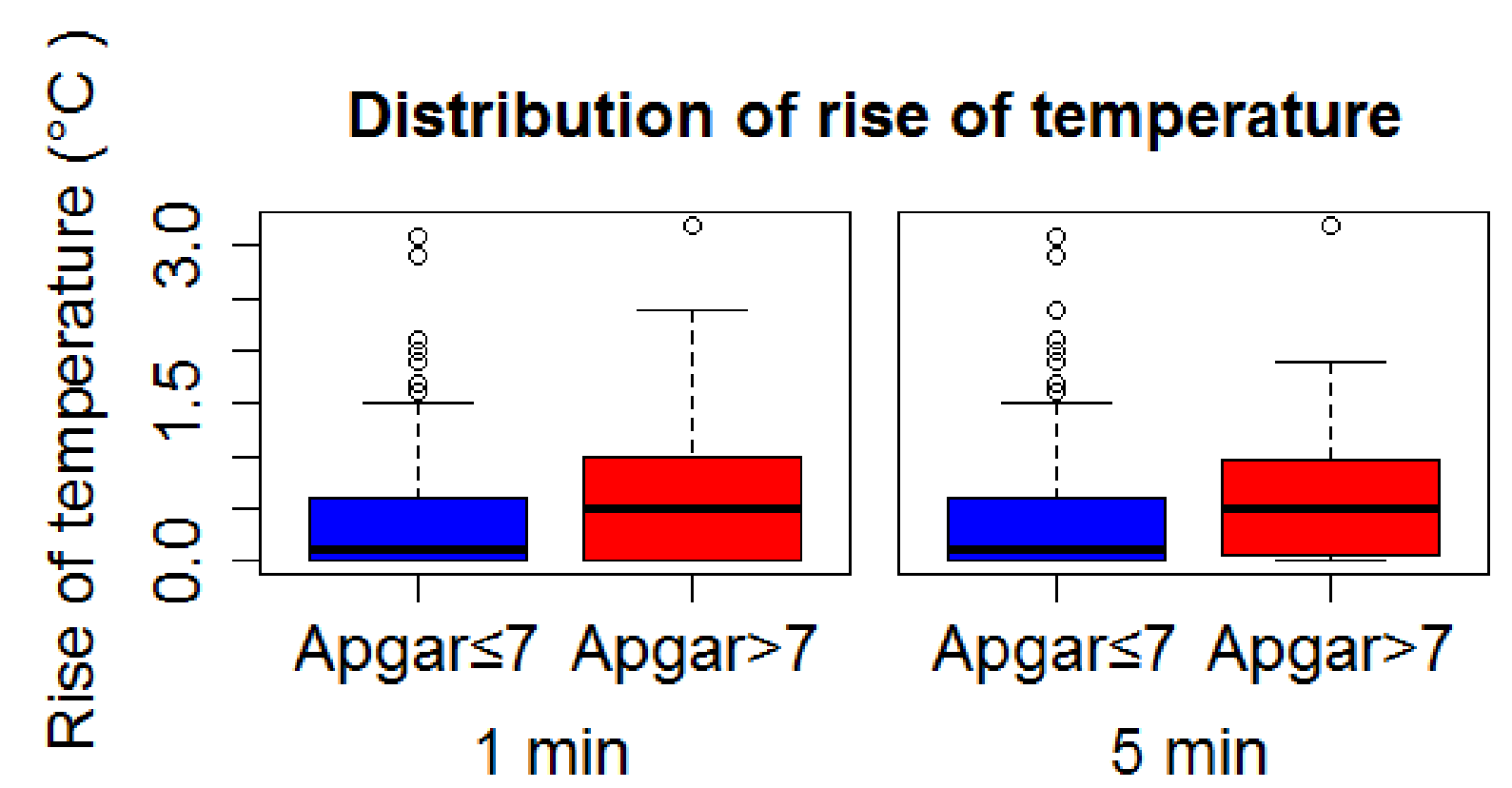

Apgar score $\leq 7$ at $1 \mathrm{~min}$ was given to $7.73 \%$, at $5 \mathrm{~min}$ to $2.95 \%$ of neonate.

Elevation of body temperature above $38^{\circ} \mathrm{C}$ was significantly associated with Apgar $\leq 7$ at $1 \mathrm{~min}(p<0.05)$, Apgar $\leq 7$ at $5 \mathrm{~min}(\mathrm{p}<0.05)$.

\section{Conclusion(s)}

The intrapartum fever is affected by longer duration of labour and anhydrous period, but it is not associated with weight gain during pregnancy, epidural analgesia, the mode of epidural analgesia infusion, the duration of epidural analgesia. The occurance of fever was associated with maternal obesity before pregnancy. Intrapartum hyperthermia negatively affects neonatal condition.

1. Kovo, Michal, et al. "Intrapartum fever at term: clinical characteristics and placental pathology." The Journal of Maternal-Fetal \& Neonatal Medicine 25.8 (2012): 1273-1277.

2. Törnell, Siv, et al. "Low Apgar score, neonatal encephalopathy and epidural analgesia during labour: A Swedish registry-based study." Acta Anaesthesiologica Scandinavica 59.4 (2015): 486495.

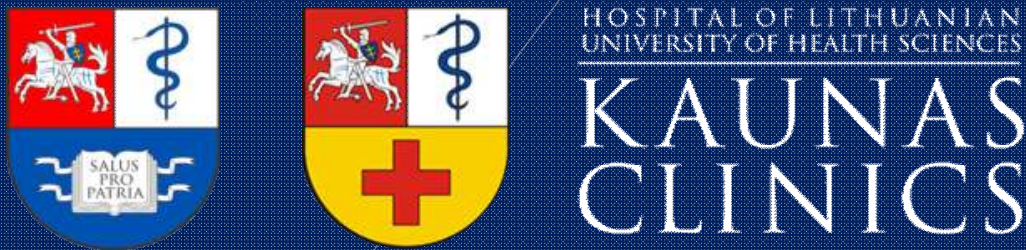

